\title{
USUTLUS VENDADE UNDUSKITEGA
}

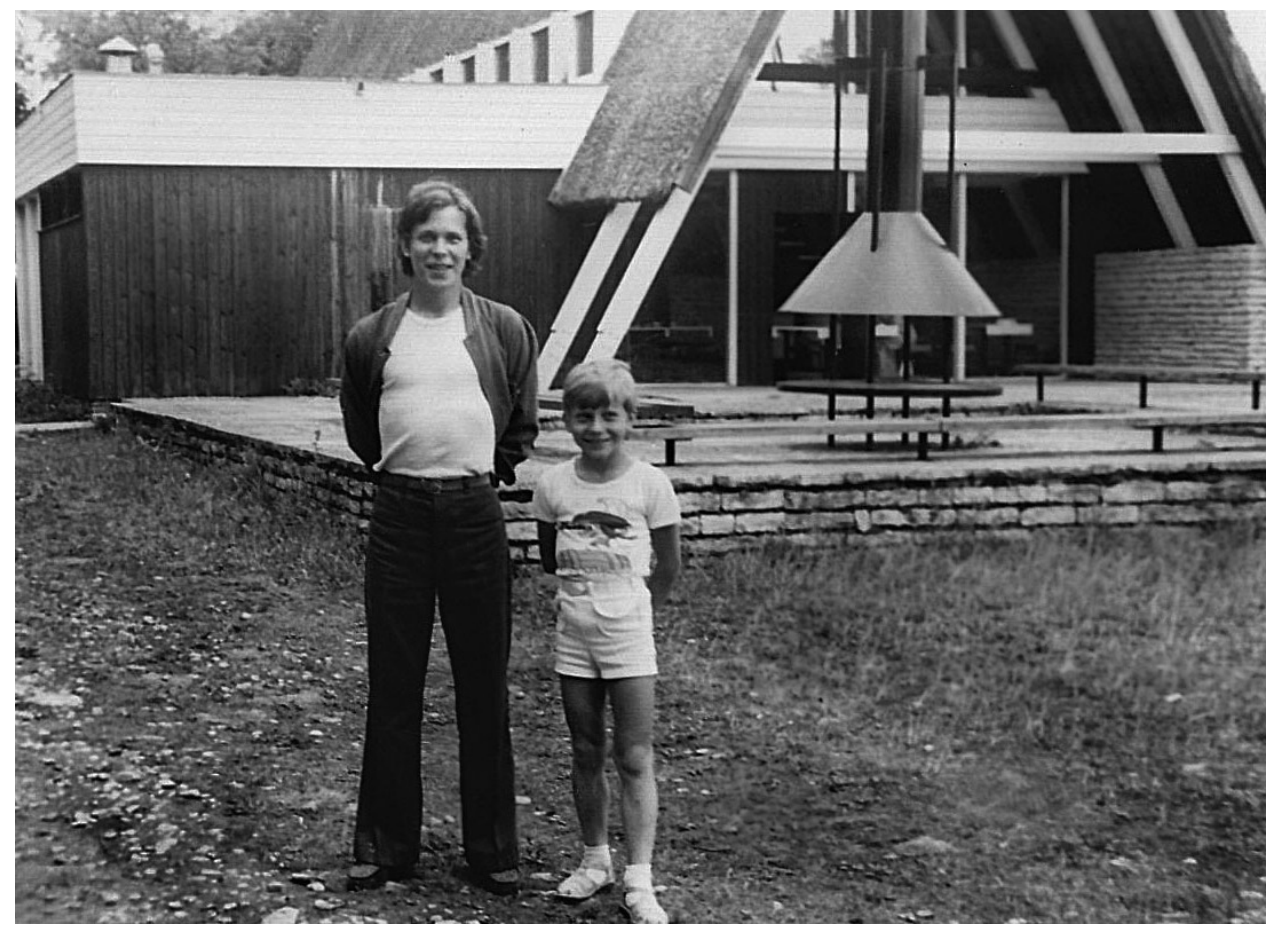

Vennad Unduskid Merepiiga kohviku ees Rannamõisas 20. juulil 1976.

Foto August Undusk, erakogu

Rein Undusk tähistas juulis oma 50. sünnipäeva, Jaan Undusk saab novembris 60. Neil mõlemal on oma eriline koht eesti kirjandusteadusliku mõtte loomises. Sünnipäevade puhul usutles neid Aare Pilv, kolleeg Underi ja Tuglase Kirjanduskeskusest. Kokku- ja lahkukõlad ei tulene vahetust vastastikmõjust: intervjueeritavad vastasid küsimustele eraldi kirja teel, siin on vastused kokku pandud.

Kuidas te ise hindate, kuivõrd on venna tegevus uurijana teid mõjutanud või ideid andnud? Kui, siis mil moel? Millisena tajute enda ja venna tegevuse ühisosa?
Rein Undusk: Tõsiasi, et läksin Tartu ülikooli eesti filoloogiat õppima, oli kahtlemata venna eeskujust ajendatud. Samas, mäletan, oli ka see mu enda kindel ja pikaaegne otsus. Ma ei läinud sinna mitte niivõrd huvist eesti keele ja kirjanduse vastu, vaid eelkõige ikka soovist kirjutada teksti - mida see pidi tähendama, teadis tollal ja teab vist praegugi vaid vanajumal ise, kuid igal juhul andsid Jaani juba tollal valminud tekstid („Etüüdid tekstist”1, „Tüpoloogia. Keel. Metastilistilised tüpoloogiad"2)

${ }^{1}$ Akadeemia 1992, nr 5, lk 974-1012; kirjutatud palju varem.

${ }^{2}$ Keel ja Kirjandus 1985, nr 9, lk 513-522; nr 10, lk 595-604; 1986, nr 1, lk 1-9; nr 2, lk 68-78. 
mulle aimu selle tahtmise suunast. See pidi ikka olema kõvasti rohkemat kui üks kirjandusuurimus. Nii et mingid mu algsed tahtmised ja hoiakud on peegeldunud kindlasti vennas. Kui oleks tollal olnud võimalik, oleksin võib-olla üritanud minna õppima filosoofiat, aga ma ei tea, kas Jaangi endale enamate võimaluste juures oleks eesti filoloogia valinud.

Jaan Undusk: Vend Rein on püüdnud leida kultuuri mõtestamiseks oma mõistesüsteemi ja alustada asju ikka mõnest teisest otsast, mitte sealt, kust mina olen juba läbi käinud. Aga siis märkan ikka ja jälle, et puutume erinevatest suundadest tulnuna mingites strateegiliselt olulistes punktides kokku. Tema kirjutab näiteks lõpmatusest, aga mina oksüümoronist kui müstilisest keelekasutusprintsiibist, mis taotleb kokkupuudet keelevälise reaalsusega. Midagi on selles suunitluses ju sugulaslikku. Meie vahel on mõnes põhimises asjas ilmselt vaikivaid kokkuleppeid. Ma arvan, et need ulatuvad kaugemale tööst kirjandusteadlase või kultuuriteoreetikuna, lähevad välja eluliselt oluliste seikadeni, eetika, maailmavaate elementideni.

Rein: $\mathrm{Mu}$ jaoks on kirjutamine alati seostunud eeskätt teatava sõnade ülesleidmise protsessiga, mille eelduseks on vastava meeleseisundi või hetketaju saavutamine. See võib vahel olla väga keeruline, aga kui see meeleseisund on käes, siis ma ideede pärast enam eriti ei muretse. Jaani rikkalik ja elegantselt vormitud ideede galerii on muidugi suurepärane avanguteoreetiline abiline, kaasaarvatult gambiitide osas.

Jaan: Kui tahaksid veel näiteid, siis oleks üks võimalikke ühisosasid absoluutsete ja relatiivsete väärtuste vahekord kultuuris. On juba aastakümneid olnud hea akadeemilis-poliitiline pruuk rõhutada põhikategooriate suhtelisust, konstrueeritavust, muudetavust, olgu siis tegu rahvustunde, ajaloo või sugudega. Suhted on alati suhtelised, juba keel annab vastuse ette. Kes nõnda ei arva, see on essentsialist, vaat et häbimärgistatud. Mina nõnda ei arva, ja tundub, et ka mu vend mitte. Inimese suhetes maailmaga peavad leiduma mingid absoluudid. Kõik küll kogu aeg miskitmoodi muutub, aga muudetavust ei saa võtta printsiibiks. Inimene peab leidma üles ka oma vastutuse. Mingid kohad, kust enam edasi ei minda. Need tuleb avastada ja siis neile mingi väljendus anda. Mis võib kesta aastaid ja jääda pooleli, põhjustada pahameelt, ilkumist, teadusmajapidamise tuiksoonest eemaldumist. Inimene, kel on tagauks pidevalt lahti, on lõppkokkuvõttes ka igav.

Rein: Põhiline ühisosa ongi see, et me mõlemad läksime ülikooli kirjutama teksti, mitte õppima eesti keelt ja kirjandust. See, mis tekstist välja on tulnud, on individuaalse andekuse, mõistuspärasuse, hullumeelsuse, tervise ja erinevate väliste asjaolude summa. Nende kõigi parameetrite osas me oleme erinevad. Jaan on väga tugeva looja-minaga professionaalne kirjutaja. Aeg-ajalt jääb mulje, et ta tahab kõike tekstiks ära teha. Mina elan pigem meeleseisundi defitsiidis. Ja selle asemel et nautida hea teksti katkematust, tunnen vahel head meelt, et olemisel on sõnad all. Pigem saadan kõik kuu peale, kui et lasen kõik ära tekstiks teha.

\section{Kas olete tundnud ka vajadust või soovi sihilikult vennast eristuda, püüda, et lähenemised ei kattuks?}

Jaan: Minu eelis on olla vanem ja võib-olla ka seetõttu pole mul sellist küsimust tekkinud. Aga ausalt öelda pole mul seda tekkinud ka kellegi teisega. Ei mingit hirmu kedagi tahtlikult või tahtmatult imiteerida või - kasutades Harold Bloomi mõistet - mõjuängi (ingl anxiety of influence). See tuleneb ilmsesti sellest, et mul on suur usaldus hästi edeneva teksti algupärasusse. Mitte nõnda, et tekst alati hästi edeneb, kaugeltki mitte, mõnikord oled kui öises tiigis, ei uju, ei upu, ka välja ei saa. Aga kui tekst käima läheb ja vedama hak$\mathrm{kab}$, siis tasub tema tõmmet usaldada. 
Mitte keegi ei kirjuta kusagil maailmas teist sellist teksti. Ja mitte keegi ei saa seda sinu eest ära näpata. Muidugi, varastada saab üksikuid mõtteid või häid formulatsioone. Aga humanitaarse teksti väärtus on enamasti siiski terviklikus mõttekäigus, mõttekulus, mõtteastes ja -astenduses, selles, kuidas üks mõte tipa-tapa jõuab mingi teise mõtte juurde ja kuidas sealt viiakse süütenöör koos kolmanda manu. Mitte filosoofia, postulaadid, vaid filosofeerimine on nauditav ja tunnetuslikult rikas. Seda copy-paste-meetodil ei saavuta. Ja seda ei saa sa ise kelleltki ega keegi sinult näpata. Seepärast pakuvad kohtumised teiste mõtlejatega strateegiliselt olulistes punktides hoopis rõõmu. Kui näed, et kaks tükki on ausalt arutledes jõudnud enam-vähem ühte kohta, siis on see jõudu andev, mitte pärssiv. Ja kui need kaks sama ausalt edasi arutlevad, siis lahknevad nende teed paratamatult taas. Ühesõnaga, eristumine, ei vennast ega autoriteedist, pole mingi probleem. Koos käidud lõigud on nagu jalutuskäigud rohelusse, alati meeldiv meenutada.

Rein: Pean ütlema, et eristumise soov on mulle võõras. Võimalik, et ma ei ole imagoloogilise probleemini oma elus veel jõudnud (tõsi, prillid tellisin küll erinevalt Jaanist endale kitsaraamilised), kuid üldiselt on mind alati enam huvitanud inspiratsioon. Ja inspiratsioonil pole mu meelest erinevusega suurt pistmist, see sünnib ikka üksnes kokkukõla tajumisest, ükskõik kui varjatud see ka ei ole. Erinevus on maise elu pärisosa, see on, võiks isegi öelda, totaalne. Mõned muusikud ütlevad, et elevandi kõrva peale astumine pole võimalik. Jutt jutuks, tõsi on see, et oma kontsertkooris nad mind näha ei soovi. Ja saate nüüd isegi aru, et kui ma selle erinevuse omaks võtan ja seda omalt poolt suurendama hakkan, siis riisun ju endalt ka lootuse osaleda siiski ühel suuremal kontserdil, mis kunagi ehk siiski leiab aset? See oleks absurdne, sest võrduks igasuguse inspiratsiooni hävitamisega.
Mida peate oma tegevuse põhiteljeks? Ja kuidas see selliseks kujunes?

Jaan: Ega midagi kõrgemat, keerulisemat ja huvitavamat ole kui inimliku eneseteostuse loogika, psühholoogilised mustrid, mille varal otsitakse teed läbi õhu. Loom läheb otse, inimesel on justkui pööritus sees. Juba ülikooliajal sõnastasin ühes kirjas sõbrale oma huvide psühholoogilise dominandi. Aga see jaguneb mitmesse harru: isiksused kui psühholoogilised mehhanismid (näiteks kirjutava inimese psühhograafia), kultuurid kui psühholoogilised mehhanismid (näiteks baltisaksa ja Eesti kultuuriruumi „ajalooline anatoomia”), kultuuriülesed psühholoogilised mehhanismid (näiteks üldine teksti- ja kirjandusfilosoofia). Need harud võivad ühes kirjutises kohtuda. Hindan kõrgelt teoreetilise mõtlemise ja kultuuriloolise eruditsiooni segunemist, kuni nende omavahelise sulandumiseni.

Rein: Meenub, et Jaan on mind kunagi nimetanud monomaaniks. See määratlus on ses mõttes täpne, et Üks on vist olnud mu põhitelg tõesti. Ühetemaatika põhjalikum väljaarendamine leidis mõtteajaloos aset Platoni, neoplatoonikute ja varakristluse väitlusväljas. Küsimus oli selles, kas on võimalik konstrueerida asjade suhtes selline vaatepunkt, mis võimaldab neist rääkida ilma neid mingis osas eitamata. Teatavasti kui me ütleme, mis miski on, siis me määratleme üht asja teise (s.o erinevuse) läbi, st eitame temas samaaegselt miskit tema osa. Neoplatoonikud leidsid, et kui selline Üks on, tuleb see üldse asetada väljapoole olemist, kristlased aga püüdsid seda oma kolmainsusliku jumala paradoksi abil hoida kinni olemise sees. Teisisõnu, küsimus on selles, kas elevandi kõrva peale astumine on marginaalne või totaalne. Ja see omakorda on oluline, sest kui marginaalne (kristlased), siis kontsert toimub, kui totaalne (neoplatoonikud), siis jääb kontsert ära. 


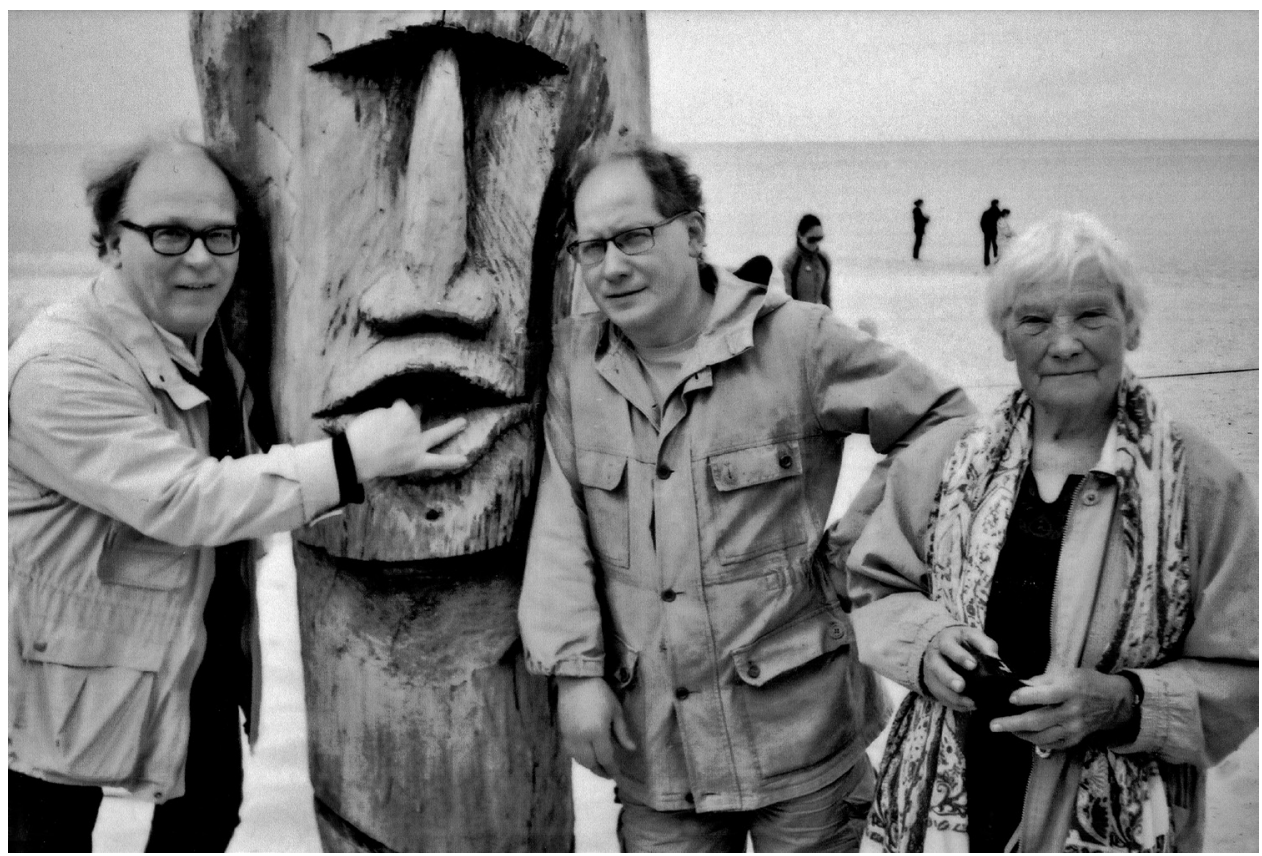

Vennad Unduskid oma ema Lindaga jaanipäeval 2017 Vääna-Jõesuu rannas. Foto: Maarja Undusk, erakogu

See Üks, mida olen oma kirjatükkides nimetanud lõpmatuseks (infiniitsuseks), aga mida võiks teatavatel tingimustel kutsuda ka suuremeelsuseks (kuus riigimeest on suuremeelsed, kui suudavad kokku leppida ühe eesistuja suhtes), on mind paelunud kui potentsiaalne kultuurikirjelduslik konstant, mis lubab modereerida kultuuriteksti n-ö avaral väljal. Platoni Ühe-otsingud (ja tema „Parmenidese” kolm esimest hüpoteesi) läksid varakristluses sujuvalt üle kolmainsuse põhjendusse ja kui filosoofia hakkas uusaja koites end teoloogiast lahti mängima, pidi ta ümber sõnastama ka oma suhte kolmainulise Jumalaga. Arvan, et kultuur kannab endas alati teatavat transtsendentsuse soovi (vajadust möönda, et asjade tõelised tähendused asuvad kuskil kaugemal), aga selle perspektiivi vormid varieeruvad ja võib juhtuda, et mingil ajahetkel asetuvad transtsendentsus ja ratsionaalsus kul- tuuris ka üsnagi kohakuti. Usun, et kultuurile tervikuna ei ole see kasulik.

Tunnistan, et tunnen praegu liialt suurt meeleseisundi defitsiiti, et olla optimistlik selle omal ajal alustatud projekti lõpule viimise osas.

Jaani telg on see, et ta on võimeline hästi kirjutama väga erinevatel teemadel. Hästi kirjutamine tähendab empiirilise tõsiasja läbivalgustamist selle psühhofüsioloogilises tingituses ühes selle tõsiasja asetamisega kultuuri vaimuloolisele kaardile. Eeskätt tähendab see aga kujundi loomist, millel tunneme kaheldamatult ära Jaan Unduski näo, aga mis vaatamata sellele justkui segavale asjaolule viib meid lähemale tõele. Sest nii naljakas kui see ka pole, tõde on kujundlik. Miks, ei tea. Mulle meeldivad kujundid seetõttu, et nad on sellised mõnusad kivised kohad, kuhu mõte võib vihmases Eesti ilmas alati kindla peale astuda. 
Saan aru, et Jaan on nüüd ühe seltskonnaga nõuks võtnud kaevuda eestikeelse kirjakultuuri eellukku. Kahtlane värk, on seal midagi leida... Aga nii näib mulle seetõttu, et ma pole algtekstidega elus suurt tegelenud, vaid olen ikka eelistanud rafineeritud kontsentraate. Kes originaali ei püüa, jääb igavesti teiseks. Loodetavasti leiavad nad eesti kirjakultuuri põuest väärt ainet, millest saab valmistada mõjusat ekstrakti.

Jaan, üks mind palju mõjutanud tekst Sinu asjade hulgast (eriti ülikooli ajal) oli „Etüüdid tekstist”, mis ilmus Akadeemias ja minu teada pole hiljem kuskil uuesti ilmunud. Kuidas Sa ise seda praegu hindad?

Jaan: Enamik mu mitmel pool ja mitmes keeles ilmunust pole autorikogumike kaante vahele jõudnud, olen olnud laisk sellise korraldustööga tegelema. Aga samas peaks mu kogutoodang oma hoiakult temaatilisele kirevusele vaatamata olema üsnagi terviklik. Kirjutan otsekui peatükke mingisse raamatusse, mille täpset pealkirja ma enam või veel ei mäleta. Märkan, et eri aegadel kirjutatu vahel leidub mõtlemise pidevusest tulenev side, iga töö haagib end kuidagi varasemate külge. Ei vaheta tekste välja, vaid kirjutan tinglikult sedasama mingist otsast edasi. Printsiip on see, et iseendal säiliks ettearvamatuse taju. Mitte nii, et künnad igal kevadel üles ühe ja sellesama põllu, vaid ikka nii, et ader on jälle kuskil kuradima kadakajuure taga kinni.

Mõnesid varasemaid kirjatöid võib nimetada lootetekstideks, sest neis on kompaktselt koos mitmeid hiljem arendatud motiive: „Tüpoloogia. Keel. Metastilistilised tüpoloogiad”, „Mõistmine kui pidevus”3, „Etüüdid tekstist”. Need olid usutunnistused, mis tuli kirja panna, enne kui järgneva juurde minna. Ühe kallal tuli piinelda nagu pikal sünnitusel, pooleli jätta ei saanud; teine tuli

\footnotetext{
${ }^{3}$ Akadeemia 1989, nr 4, lk 711-732.
}

lupsti välja. Ka need pole hiljem kusagil kaante vahel ilmunud, aga mitte seetõttu, et oleksin nad hüljanud. Ei, nad on ornamendis kindlalt paigas, alles sel aastal andsin loengu „Etüüdid tekstist" ainetel ja võisin veenduda, et minu vaatevinklist on kõik nii kui enne: näiteks, et teksti harmoonilisus ja teksti energia võivad olla väga erinevad suurused.

Ma olen vist selline, kes ei vaheta asju või inimesi meeleldi teiste vastu välja. Seda, mis on saanud elu osaks, tuleb kaasas tassida; seda, mis pole selleks saanud, pole mõtet hakata ka muu vastu vahetama.

Rein, üks Su omapäraseid tekste on bakalaureusetöö ,Arheoloogiline ja eshatoloogiline motiiv A. H. Tammsaare tekstis" $(1996)^{4}$, mis osalt jätab lausa rafineeritud poeetilise teksti mulje. Minu teada hiljem pole Sa päris sellist poeetikat/metoodikat oma kirjutistes kasutanud - kas oled nõus? Kuidas Sa seda teksti praegu hindad?

Rein: Selle teksti valmissaamisel oli oma osa külaskäikudel Tartusse Harald Peebu juurde tema Hurda tänava korteris ja õues (ning alati osavõtlikul Külvi Pruulil, kes oli seal ikka lahkelt kohvitassi ulatamas). Viisin sinna aeg-ajalt mingeid valmissaanud tekstijuppe, kuid üleliia palju me tööst ei rääkinud ja Harald ütles ka, et tal on nägemine tegelikult väga vilets. Räägin seda siin selleks, et sõnastada fraas (usun, et Harald ei solvuks selle peale) - pimesi usaldamine võib elus olla vägagi usaldust loov asjaolu. Ja tekste, nagu enamus asju siin elus, ei tehta mitte millegi muu kui usalduse pealt.

Samal suvel, peale kaitsmist, kohtasin Toomas Liivi, kes ütles, et oli luge-

${ }^{4}$ Vt R. Undus k, Arheoloogiline ja eshatoloogiline motiiv A. H. Tammsaare tekstis. - Klassika ja narratiivsus: Tammsaarest Kangroni. (oxymora 1.) Toim J. Undusk. Tallinn: Underi ja Tuglase Kirjanduskeskus, 1997, lk 59-126. 
nud, et talle meeldis, ja kutsus Roosikrantsi (s.o Underi ja Tuglase Kirjanduskeskusse).

Tollal, 1990-ndate algul oli Tartu kirjandustudengite seas tugev heideggerluse lummus. See töö on kirjutatud selle lummuse foonil. Nimetan siin heideggerluseks argumentatsiooni viisi, kus kõik otsad peidetakse lõppeks ära keelde. Pikalt viibinud töö kirjutamine sai alguse umbes punktis, kus sain aru, et Tammsaare „tegelased” võib laias laastus jagada kaheks: ühel pool on need, kes üritavad maailmas teatavat märgiehk kirjaeelset teadasaamisakti (Jussid, ussid ja pussid), ja teisel pool need (Andres), kes saavad aru, et maailm seisab tegelikult kirja peal. See Tammsaare kiri sai siis justkui mu enda kirjaks ja lisaks tekkisid huvitavad konnotatsioonid Derrida ja Piibliga. Nii et rullus lahti selline päris mõnus mitmeplaaniline kirjutamissituatsioon, mida vist naljalt enam kätte ei saa. Teostus jätab soovida, aga ma ei mõtle sellest tekstist üldse mitte halvasti. Teatav annus heideggerlust kuulub ikka tekstitegemise juurde. Küsimus on lihtsalt proportsioonides. Kihvt oleks muidugi kirjutada tõsiteaduslik arutlus, millest keegi ei saa aru, et see on heideggeriaani bluff. Aga nagu juba mõista antud, mulle meeldib keele maju ehitades mõelda päris majadele, ja vastupidi.

Kuidas te tajute, kui suur peaks olema humanitaarteadlase side parajasti aktuaalsete ühiskondlike ja kultuuriliste teemadega? Kes on suure ajalise haardega kultuuriuurija (nagu te mõlemad olete) „implitsiitne lugeja" - kas see peab tingimata olema kaasajas või kirjutate n-ö igaviku palge ees?

Jaan: Ma arvan, et iga teadlane peaks tegelema teemadega, mis talle endale on eluliselt olulised. Ja leidma lähenemisteid, mis tema oma kirgi üles kütavad. Väga vinge, kui lehetäide uurijana lahendatakse ühtlasi põletavaid elufilosoofilisi probleeme.
On alati hea, kui arukas inimene suudab avaldada julgeid ja veenvaid seisukohti oma erialavälistel ühiskondlikel teemadel. Me kõik tahaksime olla sellised ja me kõik tahaksime selliseid rohkem kuulda võtta. Ja mitte lugeda poliitikute lõputuid enesekordusi. Aga ega see julge ja veenva seisukoha kujundamine just lihtne ülesanne ole. Võtkem näiteks selline pirukas nagu Eesti Konservatiivne Rahvaerakond. Ühelt poolt on see partei kuulsaks saanud oma jõhkravõitu loosungitega, mille provokatiivsus on läbinisti ebaeluline; nendega pole suutelises poliitikas suurt midagi pihta hakata. Teisalt on see hetkel vist ainus partei Eestis, kes suudab näidata oma olemasolu vältimatust, see tähendab, ta on poliitilise võimekuse proovikivi kõigi teiste jaoks, niisiis väga eluline nähtus. Iga poliitilise pretensiooniga jõud peab astuma matile ja näitama, kuidas ta EKRE-ga hakkama saab. Aga EKRE on viinud mati niivõrd hellale pinnale, et aus kahevõitlus temaga tähendab riskeerimist oma mainega. Ja nii tehaksegi vaid põlastusžeste, tegelikult - ei sekkuta olukorda. Ning Eesti riigi tugielanikkonna mitmetele valupunktidele vajutamine on jäänud põhiliselt EKRE osaks. Sellega tuleb EKRE-le hinnangut andes arvestada ja see on tõsine jutuajamine.

Rein: Astusin eesti filli 1986. aastal, s.o ajal, mil sinna kogunesid olude sunnil veel need erinevad logose armastajad, kes on end nüüdseks edukalt ära jaganud sotsioloogia, teoloogia, psühholoogia ja muude distsipliinide vahel. Kui ajaloolased suundusid tollal peatselt tänavale poliitikat tegema, siis eesti fillid küll järgnesid neile, kuid minu jaoks on Eesti poliitilise vabaduse idee jäänud ikka mingis olulises osas filoloogiliseks ideeks tunnetada eesti keeles sõna kogu tema eksistentsiaalsel skaalal. Eesti humanitaarteadlase ühiskondlik angažeeritus tähendab panustamist sellesse eesti sõna eksistentsiaalsesse pingutusse, mitte pelgalt mingit ideoloogilist või päevakajalist kaasarääkimist. 
Mulle meeldivad suured teemad, kuid igaviku palge ees seismisele eelistan reaalseid inimpilke. Mõnest pilgust võib olla hea abi mõne teksti sünnil. Kuid üldiselt ma eriti palju ei looda ja möönan, et su teksti ainus lugeja oled võibolla sa ise. Kõik muu on kokkulepe, selle täitmine, selle rikkumine... ning kohvijoomine.

Jaan: Sa küsisid humanitaari töö igavikulise aspekti kohta. Põhiline on see, et hea humanitaarne tekst säilitab ajas oma inspiratsiooni. Olen palju tuge saanud just varasemate aegade mõtteproosast.

Psühholoogilise uudishimu rahuldamiseks uurin inimtegevuse teatavaid produkte - põhiliselt tekste, mille kohta kirjutan oma teksti. Samal ajal teadvustan endale, et minu uuringute edukuse üks tagatisi on ühtlasi see, kui esindusliku inimtegevuse produkti ma ise seda tehes valmis küpsetan. Teisisõnu, humanitaarias peab uurival tekstil enesel olema potentsiaali saada uuritavaks tekstiks - inimtegevuse representatiivseks jäljeks. Ta ei ole mitte ainult informatsiooni kandja, vaid peab huvi pakkuma ka inimtegevuse produktina. Ma tean, et see pole paljudele vastuvõetav (selles nähakse ohtu teksti „teaduslikkusele"), kuid see on minu valdav kogemus. Seetõttu ma seda primaar- ja sekundaartekstide jaotuskava, mida õppetöös kasutatakse, ei salligi. Selles elab eelarvamus, et luuletus on kirjakultuuris igal juhul esmasem selle luuletuse kohta paberile pandud esseest. Aga nii see ei ole, ühelgi tekstil pole žanriprivileegi. Iga luuletus põhineb teistel luuletustel ja iga luuletuse saab üle kirjutada. Võib kergesti juhtuda, et sekundaartekst osutub tähtsamaks inimtegevuse produktiks kui tema primaartekst. Ja kui me neid mõisteid veel edasi kasutame, siis võibki sõnastada humanitaarteadlase ülesande: sekundaarteksti kirjutamine primaartekstiks. Ehkki, nagu öeldud, need mõisted on haridusbürokraatia eksitavad leiutised.

\section{Kas kirjandusteadlane peab olema ka filosoof? Kas kirjandusteadus saab olla filosofeerimise vorm?}

Jaan: Jah, see peaks tulenema kõigest eelnevast.

Rein: Kirjandusteadlane ei pea olema filosoof. Sest vastasel korral peaks diskursivalvur hakkama temas protsentuaalselt kindlaks määrama filosoofi ja kirjandusteadlase määra, mis omakorda eeldab mõlema tüübi ekvivalendi ettevalmistamist. Segadust ja tööd kui palju. Ja üleüldse mulle ei meeldi eri keelte miksimine. Oleks minu teha, annaksin igaühele ühe instrumendi kätte ja käsiksin kogu maailm sellel pillil kuuldavale tuua. Infiniitsust maises ilmas ei väljendata mitte paljususe läbi, vaid oma piiratuse tunnistamisega. Kust järeldub, et kirjandusteadlase filosoofia on tema kirjandusele truuks jäämise korrelaat. Eesti asi on sündinud eesti kirjast ja eesti kiri on juba peaaegu sama hea kui eesti mõte. Ei ole vaja muretseda asjade pärast, mis toimuvad niikuinii. Tuleb lihtsalt pühapäeva hommikul kirikusse minna.

Küsis AARE PILV 